\section{Max Liebermann}

\section{Unsozialistischer Realismus}

\begin{abstract}
Max Liebermann gehört ohne Zweifel zu den bedeutenden Vertretern der deutschen Malerei. Wo und wie man ihn einordnen soll, damit tun sich die Kunsthistoriker allerdings immer noch schwer. Die letzte Liebermann-Retrospektive fand 2011 in Bonn und Hamburg statt und trug den Titel "Max Liebermann. Wegbereiter der Moderne". Abgesehen davon, dass diese eine jener Begriffshülsen ist, die immer dann verwendet werden, wenn Kunstkritikern gar nichts mehr einfällt - genau das war Liebermann nicht.
\end{abstract}

$\mathrm{O}$ hne Zweifel hatte der junge Liebermann ein großes Interesse und ein sensibles Gespür für die neuen Kunstrichtungen seiner Zeit. Die kamen vor allem aus Frankreich und trugen Namen wie Naturalismus und Impressionismus. Mit beiden Stilen setzte sich Liebermann intensiv auseinander. Bei seinen zahlreichen Fahrten nach Holland entdeckte er die Lebens- und Arbeitswelt der holländischen Landbevölkerung als Motiv. Aus dieser Zeit stammen auch die „Mädchen unter der Haube“ - ein klassisches Beispiel für Liebermanns Naturalismus.

Die mit der kollektiven Handarbeit beschäftigten Frauen werden unsentimental und ohne jene verklärende Romantik dargestellt, die Großstädter gerne an den Tag legen, wenn sie sich mal aufs Land begeben. Das artet dann immer rasch in Kitsch aus. Freilich verzichtet Liebermanns Darstellung auch auf jene soziale Schärfe, die später eine neue Generation von modernen Realisten entwickelte, und die schließlich in jenen „sozialistischen Realismus" mündete, der wohl zu den kitschigsten Kunstrichtungen überhaupt gehört. Der Berliner Maler Adolf Menzel, der ebenfalls das Thema der Arbeitswelt für seine Kunst entdeckte, lobte Liebermann als „den Einzigen, der Menschen macht und keine Modelle“.

Auch mit dem Impressionismus setzte sich Liebermann kreativ auseinander. $\mathrm{Zu}$ einem Markenzeichen wurde dabei seine Technik, im Rahmen von Freiluftmalerei das Licht durch das Laubdach der Bäume zu filtern und damit punktgenau kleine Teile des Bildes zu erhellen (die später sog. „Liebermann'schen Sonnenflecken"). Dies brachte dem Berliner Künstler die Bezeichnung eines „deutschen Impressionisten“ ein. Allerdings entwickelte er diese Technik Jahrzehnte, nachdem der Impressionismus in Frankreich triumphiert hatte. Liebermann war also keineswegs Wegbereiter, sondern eher ein kreativer Nachzügler.

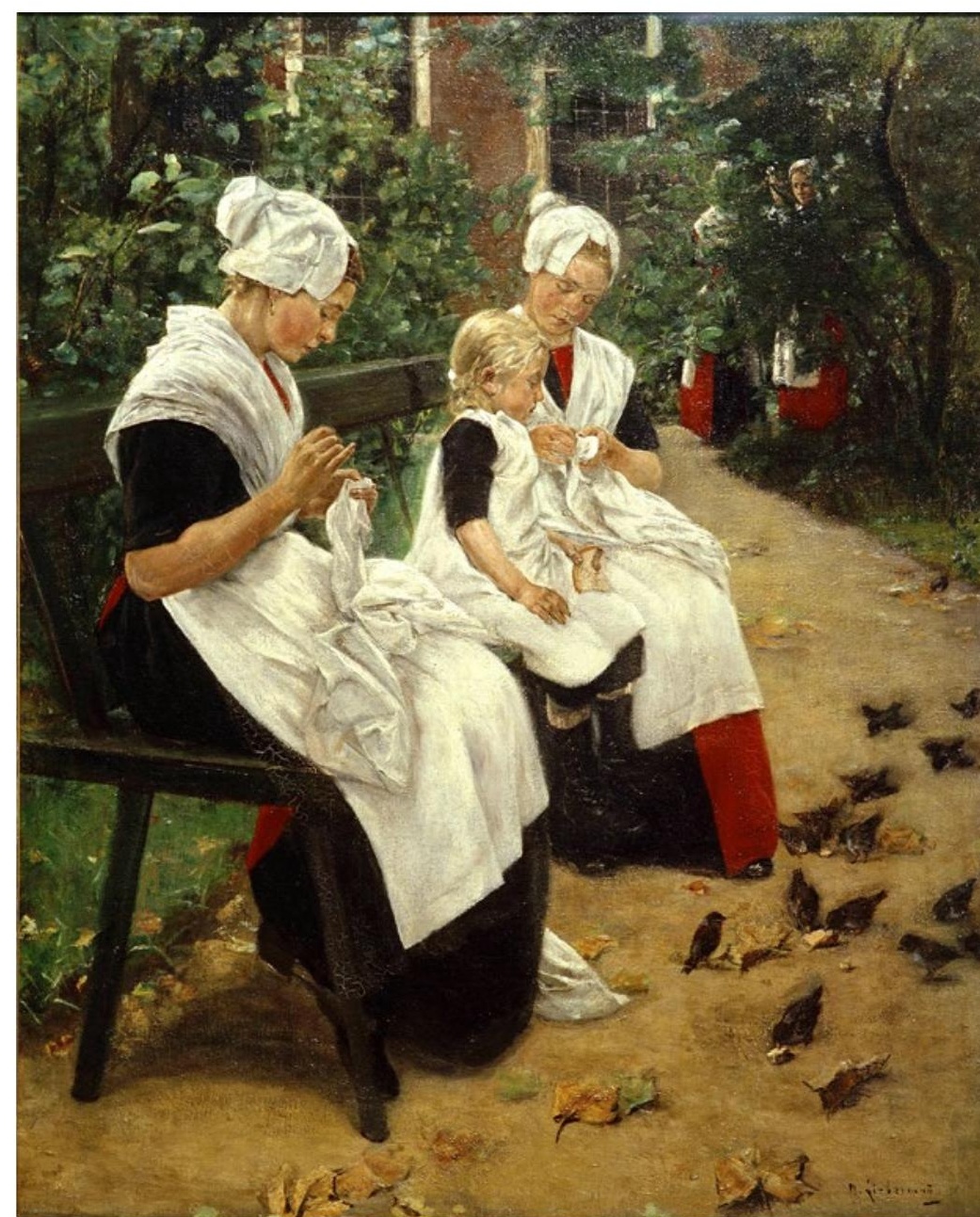

Mädchen unter der Haube, 1885, Max Liebermann (1847-1935)

Die wirkliche Moderne bahnte sich dann mit Beginn des 20. Jahrhunderts den Weg. Kubisten, Fauvisten und Expressionisten erfanden völlig neue Bildwelten und Ausdrucksformen. Liebermann bekleidete zu dieser Zeit das prestigeträchtige Amt des Präsidenten der Berliner Akademie der Künste. Mit dem Aufbruch der modernen Malerei hatte er nicht das Geringste zu tun. Vielmehr zelebrierte er die Rolle eines großbürgerlichen „Malerfürsten“, wie sie für das ausgehende 19. Jahrhundert typisch war. Liebermann war kein Vertreter der Moderne und auch nicht deren Wegbereiter, sondern ein kultivierter, konservativer Großbürger. Aber auch solche malen gelegentlich gute Bilder.

Einmal allerdings verzichtete Liebermann auf jegliche Kultiviertheit. Als er am 30. Januar 1933 auf dem Balkon seines Hauses am Potsdamer Platz den Fackelzug der braunen Horden durch das Brandenburger Tor miterleben musste, kommentierte er das im breitesten Berlinerisch mit der berühmten Äußerung: „Ick kann jar nich soville fressen, wie ick kotzen möchte.“

Wie auch immer man Liebermann als Maler einschätzt. Allein für diesen Satz gebührt ihm ein Platz in der Geschichte. Prof. Dr. med. Bernd Kleine-Gunk, Nürnberg 